\section{O Turismo e a Produção do Espaço: Perfil Geográfico de uma Prática Socioespacial}

Resumo: O turismo enquanto campo de pesquisa e estudo é multidisciplinar. Por esta razão, não pode negar às ciências que the dão suporte 0 direito de construírem métodos e teorias que lhe explicam. $O$ interesse da geografia no estudo do turismo reflete a relevância social, política, cultural e econômica que esta atividade ganhou nos últimos tempos. Além de ser um grande elemento que pode permitir o desenvolvimento econômico de regiões, o que é pertinente aos estudos geográficos, é entendido como uma necessidade social imposta pelos atuais padrões de sociabilidade, refletindo seu caráter político e cultural, tornando-o objeto de estudo importante para a geografia.

\section{Tourism and the production of the space: Geographic Profile of a Practice sociospatial}

\begin{abstract}
Tourism as a field of study and research is multidisciplinary and, therefore, can not deny the sciences that will support the right to build methods and theories that explain it. The interest in studying the geography of tourism reflects the relevance of social, political, cultural and economic activity that has gained in recent times. Besides being a major element that can enable economic development of regions, which is relevant to geographical studies, it is understood as a social necessity imposed by current patterns of sociability, reflecting their political and cultural character, making it an important object of study to geography.
\end{abstract}

\section{Carlos Henrique Costa da Silva*}

*Professor Adjunto do Departamento de Geografia, Turismo do Centro de Ciencias e Tecnologias para a Sustentabilidade da Universidade Federal de Sao Carlos - Brasil. Pos-Doutorando no Instituto de Geografia da Universidade de Buenos Aires (Argentina) bolsista do CNPq. Doutor em Geografia pela Unesp de Rio Claro.

Palavras-chave: Geografia; Turismo; Espaço Urbano; Globalização.

Key-words: Geography; Tourism; Urban Space; Globalization. 


\section{Introdução}

Dentre as ciências sociais, a geografia tem se apresentado como uma das que mais tem se aberto ao debate acadêmico sobre variados temas relevantes do período contemporâneo. A sua renovação teórica dos últimos 50 anos reflete a preocupação que a geografia tem em estudar temas atuais dentro de diversas linhas de pensamento. $O$ fenômeno da globalização é encarado por muitos cientistas da área como um importante elemento que abre caminhos teóricos e metodológicos para estudar as transformações do espaço geográfico nestes últimos anos em todo mundo. Não apenas por ser um processo que tem apresentado poucas alternativas para ser contornado, ou mesmo barrado, mas por ter permitido uma conexão em escala global de inúmeros povos, cada um com suas necessidades, características culturais, ritmos e peculiaridades, o que abriu às mais diversas partes da sociedade, a possibilidade de estar em contato, conhecer, tocar e sentir novos lugares, novas pessoas, novas culturas.

Nesta perspectiva, ressaltamos as atividades ligadas ao turismo como uma das descobertas feitas pela geografia nos últimos tempos enquanto campo de estudo. A contribuição metodológica e teórica que a geografia tem dado para o entendimento e esclarecimento dos efeitos, características e impactos do turismo é considerável. Um número razoável de pesquisadores tem se debruçado a estudar o turismo no âmbito teórico da geografia e isto auxilia no debate sobre este fenômeno social.

O turismo enquanto campo de pesquisa e estudo é multidisciplinar e, por esta razão, não pode negar às ciências que lhe dão suporte o direito de construírem métodos e teorias que the explicam. Por este motivo também, os estudos desenvolvidos no Brasil dentro do escopo restrito dos profissionais da área do Turismo têm sido muito questionados pela sua contribuição teórica, já que grande maioria tem feito estudos empiricistas que não auxiliam na compreensão teórica desta atividade. Sem mencionar a questão do clientelismo existente dentro da própria área, onde os principais profissionais, muitas vezes, desenvolvem projetos de pesquisa vinculados a interesses empresariais ou mesmo pessoais, deixando de lado, a natureza do método científico.

Assim, o presente artigo visa contribuir dentro do debate geográfico questões referentes ao turismo, destacando algumas de suas peculiaridades e características socioespaciais, para apresentar alguns subsídios sobre o seu papel na produção do espaço geográfico.

Geografia Ensino \& Pesquisa, v. 16, n.2 p. 47 - 63, maio/ago. 2012

O Turismo e a Produção do Espaço: Perfil Geográfico de uma Prática Sócioespacial

\section{Geografia e Turismo}

O interesse da geografia no estudo do turismo reflete a relevância social, política, cultural e econômica que esta atividade ganhou nos últimos tempos. Além de ser um grande elemento que pode permitir o desenvolvimento econômico de regiões, o que é pertinente aos estudos geográficos, é entendido como uma necessidade social imposta pelos atuais padrões de sociabilidade, refletindo seu caráter político e cultural, tornando-o objeto de estudo importante para a geografia. No entanto, destacamos como o principal fator para o crescimento dos estudos geográficos, o caráter espacial desta atividade.

Desde já, estamos de acordo com Cruz (2001) quando afirma que "o turismo é a única prática social que consome elementarmente espaço". Como então não ser de interesse da geografia uma prática social que utiliza, interfere, transforma, produz e consome o seu objeto de estudo? Por esta razão, cremos que a Geografia é uma importante ciência para desvendar as características formais, estruturais e funcionais que conformam a atividade turística, analisando-a na perspectiva do processo de mundialização. Assim, a contribuição da geografia leva em consideração a análise espacial do fenômeno turístico.

Rodrigues (1992) iniciou questionamentos sobre a existência de uma geografia do turismo a partir da discussão se este nome não seria uma redução da importância do turismo para a produção 
do espaço geográfico. Neste contexto, a Autora propõe o entendimento do turismo pela geografia considerando uma "abordagem geográfica do espaço do turismo", pois discute a importância epistemológica da natureza do espaço do turismo. No entanto, questionamos essa abordagem a partir da autonomia que ganha o turismo como sendo um elemento produtor de espaços específicos e únicos, o que não é verdadeiro. 0 turismo possui certamente inúmeras maneiras e modos de auxiliar na produção do espaço, porém a abordagem que a geografia deve fazer centra-se no espaço que o turismo, enquanto prática socioespacial, captura para si, tornando-o algo com características próprias. Considerar espaços como do turismo significa retirar a importância de suas demais características, como as naturais, rurais ou urbanas etc.

A abordagem geográfica do turismo liga-se a aplicação dos métodos, técnicas e teorias da geografia para a compreensão do fenômeno do turismo. Nesta perspectiva, o que emerge é uma leitura geográfica do turismo, levando em consideração os atributos naturais, físicos, sociais, econômicos, culturais e políticos do espaço que, em interação, conformam um território com características únicas voltadas para o turismo. 0 turismo representa apenas uma parcela das várias que compõem o espaço geográfico.

O turismo, tal como outras atividades - e concorrendo com elas - introduz no espaço objetos definidos pela possibilidade de permitir o desenvolvimento da atividade. Além disso, objetos preexistentes em dado espaço podem ser igualmente absorvidos pelo e para o turismo, tendo seu significado alterado para atender a uma nova demanda de uso, a demanda de uso turístico. (CRUZ, 2001, p.12)

Deste modo, estamos de acordo com Cruz sobre como o turismo é um importante fator que, tomado isoladamente ou em conjunto com as demais parcelas que compõem o espaço geográfico, produz um território bem delimitado, visível e com características muito próprias que, na atualidade, surgem com grande força em diversas partes do planeta, frutos do sucesso e crescimento que esta atividade vem tendo nas últimas décadas ${ }^{1}$. Rodrigues $(1998, p .88)$ afirma que

\footnotetext{
O tratamento geográfico do espaço do turismo é um tema de estudo que permite, pela sua abrangência, a oportunidade de ascender a um discurso unitário, superando-se a incômoda dicotomia da geografia, enquanto ciência da natureza e da sociedade.
}

Nesta questão, estamos de acordo com a Autora, pois acreditamos que o estudo do turismo revela uma unicidade na relação natureza-sociedade que fica muito difícil separar o que é natural ou artificial quando se leva em consideração a forma, a estrutura e, mais evidente, o funcionamento do turismo em um determinado local.

\footnotetext{
Desde um ponto de vista geográfico, o que fundamentalmente interessa não é tanto a estrutura econômica de um dado território, mas sim o papel do espaço, na medida em que toda atividade social, e por conseqüência toda atividade econômica, necessita, imprescendivelmente de uma base territorial na qual possa desenvolver-se. Importa, portanto, considerar a base territorial da atividade turística... (SANCHEZ, 1991, p.220)
}

Em nossa análise estamos considerando que o turismo possui características bem sincronizadas que atuam conjuntamente na produção de um determinado espaço geográfico. 0 escopo do turismo é muito maior que a utilização dos atributos naturais e culturais para atrair visitantes. Seu raio de abrangência inclui inúmeras partes que contêm diferentes setores da indústria, do comércio, dos serviços, da organização comunitária local, do poder público, da construção civil, da mídia etc.

Assim, a geografia que se foca no estudo do turismo tem pela frente um objeto diverso, em plena mutação, com muitos agentes, sujeitos e que auxilia na produção de um espaço caracterizado por uma efemeridade temporal de uso peculiar. Portanto, o que nos apresenta é uma abordagem

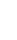 (1) \\ (1) \\ .}

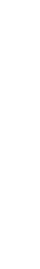


geográfica do turismo, da plenitude de suas estruturas, formas e funções, e não apenas de um espaço único de uso turístico. Acreditamos que esta visão reduz a grandeza da atividade e os seus efeitos reais no espaço geográfico. Ou seja, nossa maneira de entender o turismo revela o modo de apropriação do espaço geográfico pela prática social do turismo².

Vale lembrar, conforme Hernaux Nicolas (1996) que o que não falta no meio das pesquisas sobre turismo em geral são temas referentes à geografia do turismo, porém não fazem mais do que elencar os atributos naturais ou físicos de uma dada região ou, quando não passam a enumerar uma série de atrativos e lugares com certa atratividade, indicando a visitação, formando um verdadeiro guia turístico. Essa dita geografia do turismo está completamente fora de cogitação em estudos sobre a real contribuição geográfica no turismo. São estudos tradicionais, provavelmente realizados por não geógrafos, que não sabem a dimensão da ciência geográfica.

Por esta razão, algumas pesquisas acabaram considerando apenas parte das características da relação existente entre espaço geográfico e turismo e não a sua plenitude. Foram, na maior parte das vezes, realizadas a partir da euforia criada pelo rápido crescimento desta atividade nos últimos tempos.

A atividade turística apresentou um grande crescimento em todo o mundo a partir do fim da segunda guerra mundial. Atualmente é apontada como um dos grandes vetores de desenvolvimento social e econômico para os próximos cem anos, tornando-se uma importante ferramenta para uso político do poder público governamental. Essa tendência a maximizar os efeitos do crescimento do turismo em todo o mundo liga-se a discursos políticos, pesquisas científicas e mesmo conjecturas de mercado, que levam em consideração o aprofundamento do processo de globalização econômica nos últimos tempos. Isto se deve ao fato de que a atividade turística, se bem planejada, pensada e instituída, pode oferecer inúmeras possibilidades para a geração de emprego e renda, já que engloba importantes setores, como hotelaria, construção civil, restaurantes, franquias, parques temáticos, parques naturais, poder público, cultura, lazer, consumo, transportes etc.

2 Não estamos excluindo estudos que analisam grandes empreendimentos turísticos voltados ao lazer como resorts que foram construídos sob a égide do turismo exclusivamente. Ou ainda de grandes projetos de urbanização com características estritamente turísticas. São pesquisas importantes que apresentam uma contribuição enorme ao debate. Porém, ressaltamos que estes objetos de estudo não devem se autonomizar e, a partir deles, explicar, por exemplo, o desenvolvimento do turismo em grandes espaços urbanos, em áreas naturais, etc.

Geografia Ensino \& Pesquisa, v. 16, n.2 p. 47 - 63, maio/ago. 2012

O Turismo e a Produção do Espaço: Perfil Geográfico de uma Prática Sócioespacial

50

ISSN 2236-4994
O turismo é, incontestavelmente, um fenômeno econômico, político, social e cultural dos mais expressivos das sociedades ditas pós-industriais. Movimenta, em nível mundial, um enorme volume de pessoas e capital, inscrevendo-se materialmente de forma cada vez mais significativa ao criar e recriar espaços diversificados (RODRIGUES, 1999, p.17)

Para a ONU e seu braço responsável pelo turismo que é a OMT - Organização Mundial do Turismo, sediada em Madrid - Espanha, o turismo desde o final da II Guerra Mundial é um importante vetor de transações econômicas, sociais, políticas e culturais, já que os países, aos poucos, foram se reconstruindo e retomando importantes ligações políticas. Isso propiciou o desenvolvimento de grandes intercâmbios sócio-culturais entre as nações, o que não poderia ser deixado de lado do controle e gestão de órgãos internacionais, como a ONU. Para esta Organização

Turismo é uma atividade humana intencional que envolve deslocamento temporário de pessoas, onde 0 indivíduo permanece por mais de 24 horas e menos de 1 ano fora do local de sua residência, para a realização de qualquer atividade e satisfação de qualquer necessidade, sem intenção de lucro e se utiliza de meios de transporte, hospedagem e alimentação, dentre outros. (OMT, 2001.)

A colocação desta definição de turismo proposta pelo principal órgão do setor é interessante neste momento, pois nos basearemos nela para construir teoricamente e metodologicamente nossas reflexões. Não vamos utilizar conceitos de turismo de outros autores devido à profusão destes por parte dos mais variados profissionais da área que, a cada novo trabalho, sentiam-se no direito de introduzir uma nova definição, acrescentando ou retirando termos de outros conceitos sem realizar uma reflexão teórica sobre 0 assunto. Em nosso caso, nossas reflexões estarão centradas na ciência geográfica para estudar o turismo. Sendo assim, vamos nos centrar na definição da OMT 
e porque é a partir dela que os mais variados órgãos de turismo em nível mundial, organizam suas bases de dados, suas políticas de turismo e seus cursos de profissionalização da área.

Segundo o conceito da OMT, o turismo é uma atividade que contempla a movimentação de pessoas por um espaço material, considera um tempo de deslocamento, a utilização de uma variada gama de serviços que permitem às pessoas esse trânsito, bem como a utilização de serviços básicos/complementares que vão dar suporte a essa movimentação (hotelaria, transporte, alimentação etc.). Além disso, no conceito fica expressa a questão da realização pessoal contida na prática desta atividade, ou seja, a partir do turismo tem-se o cumprimento da satisfação de certas necessidades, ligadas ao consumo, ao lazer, ao prazer, à saúde etc.

É relevante destacar deste conceito os termos atividade humana intencional. Ou seja, o turismo ocorre quando há uma intencionalidade. Estes termos devem ser entendidos de duas formas: uma que considera o ato de viajar uma vontade ou intenção que é inerente à personalidade humana que tem forte em si, o senso de descobrir o novo, de estar em contato com novas culturas, conhecer pessoas, lugares, experimentar, usufruir o tempo livre na forma de viagens. $O$ outro é a construção de uma obrigação do ato de viajar na atualidade, pois viajar hoje não significa apenas canalizar as energias para curtir momentos de lazer, por exemplo. Viajar tornou-se uma imposição social. Quem viaja conhece mais, experimenta mais, tem mais assuntos, possui maior formação pessoal. E assim, viajar passou a significar consumir excessivamente bens que comprovem que 0 cidadão realizou verdadeiramente aquela viagem. A partir destas considerações pode-se perceber a contemporaneidade deste conceito e o caráter econômico e social que possui o turismo.

Cruz (2001) destaca neste conceito da OMT o seu caráter abrangente, pois, por ele, percebe-se que qualquer tipo de viagem, independente da motivação do deslocamento, passa a ser considerada turismo, o que interfere demais nas estatísticas locais, regionais, nacionais e mundiais do setor. No conceito da OMT há uma similitude entre viagem e turismo. Ou seja, uma pessoa que esteja viajando para tratar de saúde é equiparada nas estatísticas aos turistas de um resort especializado em lazer, às viagens de férias de fim de ano de adolescentes, a um executivo que viaja diversas vezes ao ano a negócios etc.

Este fato fica mais evidente conforme destaca Cruz (op.cit), quando afirma que a lógica que rege os espaços para o uso turístico é a do lazer.

\footnotetext{
... todo viajante é, para os organismos oficiais de turismo, um turista potencial, pois pode tal como alguém que viaja por motivo de lazer, utilizar-se total ou parcialmente das infraestruturas turísticas presentes no destino. Não se pode negligenciar o fato, entretanto, de que, ao abarcar todo tipo de viagem como turística, a definição oficial de turismo conduz, entre outras coisas, à exacerbação das estatísticas. (CRUZ, 2001, p.5).
}

Estas considerações têm sua pertinência em razão de dar maior valor ao turismo, com dados apresentando taxas de crescimento cada vez maiores, incluindo toda e qualquer pessoa que se desloca territorialmente como um turista.

\section{O Espaço Geográfico frente ao desenvolvimento do Turismo}

Os dados sobre o crescimento da atividade turística em todo mundo, revelam uma linha ascendente forte até 2001, quando ocorreram os atentados terroristas nos Estados Unidos, e então há uma quebra nesta ascensão. Em 2002, os números voltam a crescer, mas 2003 apresentou forte queda devido, principalmente, às doenças SARS (gripe do frango) na Ásia. No entanto, contornada esta barreira, o crescimento já se mostra em ascensão novamente. A tabela 1 apresenta esses dados.

Através da tabela 1, pode-se visualizar o rápido crescimento em nível mundial dos deslocamentos de pessoas ao redor do globo. Estes dados expressam a entrada e saída de

Geografia Ensino \& Pesquisa, v. 16, n.2 p. 47 - 63, maio/ago. 2012

Silva, C. H. C.

ISSN 2236-4994 | 51 
estrangeiros de cada país, ou seja, quando um cidadão ultrapassa suas fronteiras nacionais ele é registrado, servindo de base para estas estatísticas. Isto é a base para a realização de rankings, por exemplo, dos países e cidades mais visitadas em todo o mundo.

Tabela 1- Fluxo e receitas advindas de turistas internacionais em todo mundo entre 1965 e 2010.

\begin{tabular}{|c|c|c|c|}
\hline ANOS & TURISTAS (Milhões) & ANOS & $\begin{array}{c}\text { RECEITA (Bilhões } \\
\text { de US\$) }\end{array}$ \\
\hline 1965 & 112,9 & 1965 & 11,6 \\
\hline 1970 & 165,8 & 1970 & 17,9 \\
\hline 1975 & 222,3 & 1975 & 40,7 \\
\hline 1980 & 286,1 & 1980 & 102,4 \\
\hline 1985 & 327,2 & 1985 & 116,2 \\
\hline 1990 & 441,2 & 1990 & 230,6 \\
\hline 1995 & 538,1 & 1995 & 399,0 \\
\hline 2000 & 680,6 & 2000 & 460,1 \\
\hline 2005 & 802,5 & 2005 & 679,5 \\
\hline 2006 & 861,1 & 2006 & 723,9 \\
\hline 2007 & 902,6 & 2007 & 858,6 \\
\hline 2008 & 919,9 & 2008 & 941,9 \\
\hline 2009 & 885,3 & 2009 & 852,5 \\
\hline 2010 & $907,9^{*}$ & 2010 & $889,6^{*}$ \\
\hline
\end{tabular}

* Projeção Fonte: Highlights, OMT, 2010 * Projeção Fonte: Highlights, OMT, 2010

Quando se acrescenta o dado de fluxo de dinheiro que gira no setor do turismo, as estatísticas ganham importância ainda maior. Conforme a OMT, em 1990, o turismo gerava em todo o mundo, US\$ 230 bilhões. Atualmente, esta cifra já ultrapassa a casa dos US\$ 700 bilhões, sendo projetado para 2010 alcançar US $\$ 1,006$ trilhão. Estes números são tão enlarguecidos, pois as políticas nacionais de desenvolvimento do turismo passaram a se disseminar em variados países, já que o investimento neste setor pode trazer, de maneira rápida, grandes dividendos devido ao sucesso apresentado em outros países, sobretudo na Europa e em algumas ilhas do Caribe. Países da Ásia como Cingapura, China, Emirados Árabes Unidos e Tailândia investiram maciçamente na construção de atrativos locais que impulsionaram fortemente as viagens a seus territórios. No caso asiático, as motivações foram variadas, porém, destacam-se a dos negócios e a de conhecer culturas exóticas, até então "fechadas" ao mundo.

Naisbitt (1994), baseando seus estudos em dados do início dos anos noventa destacava a importância do turismo na geração de empregos. Este autor afirma que em 1993 o turismo empregava 204 milhões de pessoas. Atualmente a OMT garante que são mais de 550 milhões de pessoas que trabalham, de algum modo, ligadas ao turismo. Porém, vale destacar mais uma vez que não há uniformidade ou segurança nesses dados, já que são colocadas nas mesmas estatísticas, dados colhidos de países europeus e africanos com realidades de controle e normatização destes num mesmo plano. Além disso, o turismo é uma das atividades econômicas com mais alto grau de informalidade. Dificilmente 0 vendedor de coco, 0 artesão, 0 ambulante está registrado nas

Geografia Ensino \& Pesquisa, v. 16, n.2 p. 47 - 63, maio/ago. 2012

O Turismo e a Produção do Espaço: Perfil Geográfico de uma Prática Sócioespacial

52

ISSN 2236-4994 prefeituras e paga impostos sobre a circulação de mercadorias. Assim, são dados que temos que relativizar em nossas análises.

Apesar disso, tem que se levar em conta que o turismo é uma prática que interfere na circulação de bens, serviços e pessoas e só isso já dá relevância para se dedicar a seus efeitos no espaço geográfico.

Conforme Hernaux Nicolas (1999) o turismo cria, transforma e valoriza espaços diferentemente de outras atividades, pois provavelmente, estes locais não poderiam ter valor na lógica da produção 
industrial, mas que podem ser encarados, incorporados e valorizados pela lógica do ócio e do turismo.

Todo e qualquer lugar do planeta pode ser considerado espaço de uso e apropriação do turismo, pois esta prática é socialmente e culturalmente construída, e hoje, ainda mais evidente, pois ela é imposta enquanto um ato de sociabilidade.

\begin{abstract}
Considerando que os espaços são diferentemente valorizados pelas sociedades, em função das possibilidades técnicas que determinam sua utilização, de fatores políticos, econômicos e, também, culturais, todo o espaço do planeta (e mesmo de outros planetas) pode ser considerado espaço do turismo. (CRUZ, 2001, p.12)
\end{abstract}

Do ponto de vista econômico, um lugar com forte presença da prática turística pode perder sua atratividade em determinado momento se o país onde se localiza, sofre uma grande crise econômica ou mesmo política que interfira demasiadamente no seu processo de reprodução espacial. Isto pode se intensificar se as empresas que articulam o turismo aí são estrangeiras e passam a sentir um clima de instabilidade que venha a interferir em seus lucros, fazendo com que estas se retirem do lugar, deixando-o, levando consigo toda a imagem de beleza, simplicidade, exclusividade ou naturalidade dali. A derrocada deste lugar se dará por meio da dispensa de trabalhadores em massa, queda do nível de rendimentos, desestruturação social e econômica, retirando-o do circuito turístico regional, nacional ou mundial.

Do ponto de vista cultural, os lugares que têm no turismo sua base de vida, também sofrem uma grande sazonalidade. Entendemos aqui a sazonalidade no sentido de que um lugar pode ser considerado o mais exclusivo, novo, divertido em um determinado momento histórico e em outro, ser deixado de lado, perder atratividade, e mesmo o movimento inverso. Isso ocorre devido a diversos fatores ${ }^{3}$, mas que estão ligados principalmente à importância que é dada àqueles lugares como os principais centros de turismo do momento, que devem ser conhecidos por todos aqueles viajantes que se consideram na avant premiere do mundo. Ou seja, a produção, divulgação, venda e consumo dos lugares está ligada a uma temporalidade que é efêmera.

Brasileiros que viajavam a Portugal na década de 1970, o faziam por ser um destino barato, que não tinha problemas graves de comunicação devido às facilidades com a língua e não consideravam Portugal como sendo um país pertencente à Europa. Isto porque o país possuía nível de desenvolvimento muito inferior a seus vizinhos. Hoje, parte desta situação permanece, mas viajar a Portugal não é mais sinônimo de não conhecer a Europa, porque este país faz parte da união européia, utiliza da moeda euro, renovou e construiu novos atrativos, aumentando sua atratividade, colocando-o entre os países mais visitados do mundo. É um dos países europeus mais visitados por brasileiros na atualidade.

Além disso, podemos citar também, cidades que desenvolviam uma grande atratividade num determinado momento da história e que, atualmente, a perderam. Um exemplo próximo da realidade do Estado de São Paulo é a cidade mineira de Poços de Caldas. Também na década de 1970, Poços de Caldas era considerada uma destinação clássica para viagens de Lua de Mel. Hoje, a cidade tenta diversificar seus atrativos para tentar voltar a ter $50 \%$ do glamour e do nome que tinha naquela época. Isso porque os padrões sociais e de mercado que garantiam que Poços de Caldas fosse uma viagem interessante mudaram. Outras cidades surgiram vendendo o mesmo produto com preços mais competitivos e com outras facilidades e exclusividades. $O$ perfil dos tipos de viagens proticadas também mudou, ou seja, o turista ampliou seu leque de opções e viu também modificada seus desejos de viagem. 0 mercado das destinações turísticas é muito dinâmico. Em menos de dois anos um local pode sair deste circuito e ficar à margem.

O caso dos países do Leste Europeu é um caso bem peculiar da interferência política no desenvolvimento do turismo. República Tcheca, Hungria e Polônia figuram hoje entre os países que mais recebem turistas estrangeiros em todo o mundo. Há 20 anos atrás, eles nem apareciam
3 Alguns pesquisadores desenvolveram métodos que contemplam um ciclo de vida das destinações turísticas, apresentando diversas etapas que explicam o ganho ou perda de importância de atrativos, cidades e países no rol das destinações turísticas. Para mais, consultar Ruschmann (1998).

Geografia Ensino \& Pesquisa, v. 16, n.2 p. 47 -63, maio/ago. 2012

Silva, C. H. C.

ISSN 2236-4994 | 53 
entre os 50 mais. Isto porque havia uma barreira política intransponível para época que era a dualidade ocidente/oriente, capitalismo/socialismo que se materializava especificamente nesta porção da Europa, "escondendo" ou não dando visibilidade, ao grande patrimônio histórico cultural pertencente a estes países. Com a queda da "cortina de ferro" houve uma verdadeira invasão de turistas advindos dos países da Europa Ocidental para estes países. As motivações eram as mais diversas, mas principalmente pelo atrativo dos preços baixos e a vontade de conhecer estas culturas. Atualmente Praga é uma das cidades mais visitadas da Europa e sua visibilidade já alcançou inclusive os grandes estúdios de cinema norte-americano, que passaram a filmar ali algumas produções, levando o nome da cidade para todo o mundo.

Porém o movimento inverso também é bem evidente. Por vontade política, investimentos econômicos e pela cultura, uma cidade, região ou país pode passar a receber, ou parar de receber, hordas de visitantes.

A dinâmica da produção de territórios turísticos (ou seja, da apropriação dos espaços pela prática social do turismo) comporta, com a incorporação de novos espaços, o abandono parcial ou total de outros, pois, entre os fatores que determinam sua valorização, destacamse os modismos, produzidos pela ação determinante do marketing. (CRUZ, 2001, p.12)

A partir desta citação percebe-se a dinâmica do mercado turístico em todo o mundo. A ação do planejamento territorial voltado para o turismo é muito objetiva quando se tem a meta de construir uma nova área, em qualquer lugar do planeta, para uso turístico.

Para que possa ocorrer o planejamento e desenvolvimento de um determinado território turístico, são priorizadas algumas localidades que preencham certos requisitos básicos, como possuir um mínimo de infra-estrutura, serviços, acessos e contar também com algum tipo de potencial para o turismo. Não é tão simples para que um lugar possa ser inserido nas rotas do turismo. Sua potencialidade e vigor turístico são medidos e assim, sua vocação natural pode ser potencializada a partir de investimentos de capital em diversos setores, mas principalmente em infra-estrutura de uso turístico (hoteleira, restauração, arte, cultura), atrativos e qualificação profissional, para que possa ter um mínimo de atratividade e oferecer conforto ou diferenciais para setores do mercado consumidor.

Segundo Cruz (2001, p.12) "a intensificação do uso turístico de dada porção do espaço geográfico leva a introdução, multiplicação e, em geral, concentração espacial de objetos cuja função é dada pelo desenvolvimento da atividade". Assim, fluxos de capital, informações e pessoas externos a localidade que passa a ser vista como foco dos investimentos em turismo, se direcionam em um ritmo muito rápido para que este local possa, na maior velocidade possível, entrar no rol das destinações turísticas mais modernizadas.

A indústria do turismo tem produzido espaços delimitados e especialmente destinados a variados tipos de consumo através dos denominados serviços do turismo, que envolvem uma gama extensa de empresas e pessoas que articulam os atrativos que o turismo se apropria, (naturais, culturais e construídos) para uso dos turistas.

Enquanto a indústria do turismo articula a produção e consumo de um espaço, os serviços fluem por este mesmo espaço, através dos agentes produzidos pelo processo de mundialização, que veio se aprofundando a partir da década de 1970, com o uso cada vez mais intenso de ciência

Geografia Ensino \& Pesquisa, v. 16, n.2 p. 47 - 63, maio/ago. 2012

O Turismo e a Produção do Espaço: Perfil Geográfico de uma Prática Sócioespacial e tecnologia no cotidiano das sociedades. Deste modo, as informações sobre os lugares, suas belezas, potencialidades e materialidades circulam através de imagens, fotografias, jornais, revistas e internet, de forma cada vez mais rápida, auxiliando no crescimento da atividade turística ao redor do mundo. Um lugar por mais inóspito que seja, pode tornar-se, de uma hora para a outra, de uso turístico e ser cooptado pelos seus agentes para o consumo de seus bens intrínsecos.

Knafou (1996) apresenta que os principais agentes que interferem na turistificação dos territórios são: os turistas, o mercado e os planejadores e promotores territoriais. 
Os turistas são os grandes consumidores do espaço. Sua afluência até determinado local, interfere no sucesso ou derrocada de um empreendimento. A chegada destes ${ }^{4}$ é entendida para aqueles que trabalham no setor, como um sinal de que os investimentos foram bem aplicados e 0 retorno estará garantido, ou não.

0 mercado é quem gerencia e coordena a sazonalidade e o uso dos lugares turísticos. Com o controle dos preços de passagens aéreas, diárias de hotel e serviços de alimentação, por exemplo, os agentes do mercado podem selecionar o tipo de visitante que aquela localidade tem condições de receber. Viajar hoje ao Taiti não é para qualquer turista. É um lugar muito distante dos maiores centros emissores do mundo, são poucas as companhias aéreas que voam para lá, controlando os preços, já que a concorrência é pequena. Além do mais, são em número reduzido os meios de hospedagem existentes nas ilhas, valorizando os que estão em funcionamento atirando os preços às alturas.

O mesmo movimento ocorre no lado de baixo de uma possível pirâmide de renda do turismo. No topo estão os destinos mais exclusivos com preços altos voltados para clientes endinheirados de todo o mundo. Na base estão locais onde há uma popularização do uso das infra-estruturas turísticas. No Brasil, um bom exemplo é a cidade baiana de Porto Seguro. Este município sofreu uma verdadeira invasão de empresas turísticas nos últimos 15 anos, e com elas, muitos turistas. Atualmente, é um destino relativamente barato para quem compra um pacote de viagem com transporte, hotel, alguns passeios e parte da alimentação, utilizando os serviços de uma agência de viagem. Além disso, as facilidades de pagamento (dez parcelas no cheque ou cartão de crédito) ampliaram ainda mais as possibilidades dos brasileiros inseridos na prática do turismo, de viajar de avião, se hospedar em hotel com serviços de praia, por exemplo.

Vale lembrar que essa dinâmica do setor reflete as características do movimento da sociedade em diferentes tempos. Na história da viagens vê-se que diferentes lugares ao redor do mundo tinham maior ou menor atratividade. Na Roma Antiga, as fontes termais eram os destinos mais aprazíveis. Na Idade Média Ocidental, ir a praia não significava nenhum tipo de forma de lazer, já que a clausura da vida comandada pelos ensinamentos da Igreja Católica não permitia ter prazer com o corpo. Diversas montanhas, campos, florestas já se alternaram como grandes produtores de atratividades. Acreditamos que isso procede devido a valorização cultural que determinadas práticas ganham ao longo da história.

Hoje ir a alguma cidade de praia durante o ano, no Brasil, significa curtir momentos de lazer extremos. Em épocas como o Carnaval quem não vai a uma cidade de praia, excetuando-se locais onde a cultura do carnaval ainda é preservada nas comemorações ao redor das ruas do centro histórico, é levado quase ao limbo nas conversas cotidianas. Estamos de acordo com Cruz (2001, p.13) que afirma que "a valorização dos espaços pelo turismo é dada em função de valores culturais e a cultura é própria de cada grupo social e mutável no tempo, territórios eleitos pelo turismo hoje não correspondem, necessariamente, aos territórios turísticos de amanhã".

Outro agente apresentado por Knafou (1996) são os planejadores e promotores territoriais. Fazem parte desta categoria o poder público, por meio das superintendências, secretarias, agências, bancos de desenvolvimento regional, nacional, municipal que focalizam investir em infra-estrutura (viária, sanitária, energia) e empresas de planejamento territorial que incorporam, constroem e vendem os mais diversos empreendimentos para uso turístico. Neste caso, o maior peso é dado ao poder público que também tem a tarefa de construir uma série de infra-estruturas legais para controlarem o ritmo da promoção de um determinado local. Nesta direção, vale citar Cruz (2002, p.9) quando discute o papel do poder público no desenvolvimento de políticas públicas voltadas ao desenvolvimento turístico.

O modo como se dá a apropriação de uma determinada parte do espaço geográfico pelo turismo depende da política pública de turismo que se leva a cabo no lugar. À política pública de turismo cabe o estabelecimento de metas e diretrizes que orientam 0 desenvolvimento socioespacial da atividade, tanto no que tange à esfera pública como no
${ }^{4}$ Vale lembrar que a categoria turista é um estado. Todos nós podemos ser turistas algum dia. Assim, não podemos encarar os turistas como seres externos a sociedade que somente trazem malefícios ou benefícios para o lugar.

Geografia Ensino \& Pesquisa, v. 16, n.2 p. $47-63$, maio/ago. 2012

Silva, C. H. C.

ISSN 2236-4994 $\mid 55$ 
que se refere à iniciativa privada, na ausência da política pública, o turismo se dá à revelia, ou seja, ao sabor de iniciativas e interesses particulares.

Alguns estudos importantes já discutiram o papel destes agentes na promoção e planejamento territorial. Cruz (2002) analisou a urbanização turística no litoral do nordeste. Bertoncello (1998) analisou o papel dos agentes imobiliários no desenvolvimento de balneários no litoral argentino. Luchiari (1998) discutiu a questão da urbanização turística num mundo global, onde as ordens e normas locais são ditadas à distância do lugar, produzindo estranhamentos. Almeida (1998) faz análise das políticas territoriais de turismo no litoral do Ceará. Yazigi (2001 e 2003) discute assuntos sobre a força do planejamento turístico na imagem de determinadas localidades. Rodrigues (1999) traça um perfil das contribuições da geografia para o desenvolvimento dos estudos em turismo.

Estas pesquisas têm revelado o papel dos agentes do turismo na produção do espaço destacando os problemas, efeitos e impactos negativos e positivos que esta atividade imprime na comunidade local onde se desenvolve o turismo. Todas apresentam uma crítica importante do papel do poder público no diálogo entre agentes e promotores imobiliários, empresas do trade turístico e segmentos da comunidade. Um ponto em comum nestas pesquisas é o consenso sobre a relevância da prática do planejamento, seja territorial, urbano, turístico, setorial ou estratégico no desenvolvimento de qualquer tipo de empreendimento voltado ao turismo, sob a supervisão dos governos municipais, estaduais e federal no encaminhamento desta prática.

Conforme enfatizou Cruz (op.cit), se não há uma rigorosa supervisão e controle do desenvolvimento do turismo por parte dos governos, deixa-se as principais decisões a cargo das empresas que só visualizam retirar proveito (lucro) naquilo que estão investindo segundo seus próprios interesses, sem pensar nas condições de vida da comunidade local, do meio ambiente, do patrimônio histórico-cultural.

Sobre este assunto é interessante destacar a questão da urbanização turística que está se processando em diversas partes do Brasil. É um movimento que expressa a força que é outorgada aos agentes promotores do turismo, por grandes grupos empresariais brasileiros e estrangeiros. A urbanização turística coloca as cidades no mercado de paisagens naturais e artificiais. Nas palavras de Luchiari (1998, p. 17), "algumas cidades chegam a redefinir toda sua vida econômica em função do desenvolvimento turístico, reorganizando-se para produzir paisagens atrativas para o consumo e para o lazer".

\section{Considerações Finais}

A "chegada do turismo" pode acarretar grandes transformações no espaço urbano. Para algumas regiões o turismo se coloca como única alternativa para o desenvolvimento econômico, deixando à mercê de agentes externos os caminhos da comunidade local. Isso ocorre quando uma vocação turística é construída ou imposta, levando uma lógica estrangeira a certos locais, fazendo com que este lugar se transforme para reproduzir uma nova configuração sócio-espacial. "O turismo reinventa e cria novas funções, recupera antigas práticas e bens culturais por meio do folclore e monta atrações turísticas para a região". (LUCHIARI, 1998, p.15)

0 destaque é dado para grandes modificações que ocorrem no espaço urbano tornando-o

Geografia Ensino \& Pesquisa, v. 16, n.2 p. 47 - 63, maio/ago. 2012

O Turismo e a Produção do Espaço: Perfil Geográfico de uma Prática Sócioespacial 
o consumo de bens, serviços e paisagens. Enquanto - desde a Revolução Urbana - as cidades eram construídas para a produção e para as necessidades básicas, estas cidades erguem-se unicamente voltadas para o consumo e para o lazer. (LUCHIARI, 1998, p.17)

Knafou (1996) apresenta uma interessante metodologia para a classificação das relações entre turismo e espaço geográfico. A partir da noção de territórios produzidos pelo e para o turismo, ou seja, a forma espacial assumida pelo turismo (CRUZ, 2001, p.19), este Autor apresenta três possibilidades de relação do turismo com o território.

A primeira possibilidade seriam os territórios turísticos, ou seja, territórios construídos exclusivamente para a ocorrência da prática turística. Neste caso, incluem-se todas aquelas cidades que foram planejadas e criadas tendo o turismo como sua principal fonte de produção de renda. Seja qual for sua atratividade, o turismo é a base da vida da cidade ou da região. Nesta possibilidade, inserem-se até alguns países como algumas ilhas do Caribe que têm no turismo sua maior e única fonte de renda. Destacam-se também, grandes locais privados onde o turismo comanda uma série de atividades no entorno destes empreendimentos. Como exemplos, incluemse os parques temáticos e os mega resorts.

A segunda possibilidade seriam os territórios sem turismo. Na verdade, o Autor se refere a algumas partes do planeta que ainda não foram cooptadas ou descobertas pelos agentes do trade turístico. Neste caso, inclui-se uma série de lugares aonde o turismo ainda não chegou. Vale lembrar, como já destacamos que o turismo é uma prática sócio-espacial extremamente dinâmica que tem na cultura um de seus principais fundamentos. Deste modo, um local pode não conter atratividade hoje, mas poderá ganhá-la amanhã.

A terceira possibilidade destacada é a de turismo sem território. Knafou (op.cit) apresenta os center parcs europeus como um exemplo da existência do turismo sem um território, ou melhor, o turismo existe sem que haja nenhuma relação genética com o local de sua materialidade. Os center parcs europeus caracterizam-se por estarem descolados do seu entorno, configurando-se como grandes parques temáticos construídos para existirem fora de contexto. São simulacros que têm a capacidade de existirem ignorando as condições físico-naturais. É um objeto que mostra a capacidade do capital para interferir na reprodução do espaço com uso turístico. Os maiores exemplos de center parcs são aqueles que reproduzem um ambiente tropical no continente europeu em pleno inverno, com florestas, praias, rios, bananeiras e uso de biquínis já que a temperatura interna é de aproximadamente 250 e a externa ao redor de zero grau. Neste caso, estamos de acordo com Cruz (2001, p.22) quando afirma que

\begin{abstract}
As chamadas potencialidades turísticas (naturais e/ou culturais) de um lugar já não são mais determinantes da escolha, por parte do mercado, de uma ou outra porção de território para implementação de alguma estrutura para uso do turismo. Os progressos da ciência, da técnica e da informação permitem que estruturas absolutamente indiferentes ao seu entorno sejam implantadas nos territórios.
\end{abstract}

Muitas vezes a atratividade de um lugar, ou seja, suas belezas naturais, do patrimônio arquitetônico ou mesmo festas populares, etc., perdem valor para os próprios serviços turísticos da localidade. Quando se hospeda em um resort ou realiza um cruzeiro de navio, dificilmente o turista se retira destas infra-estruturas para explorar o entorno, no caso dos resorts, ou visitar as cidades localizadas nas paradas dos navios.

Essas três possibilidades de existência de territórios voltados para o turismo mostram a permanente necessidade de criação de novos produtos e novos lugares, para serem consumidos através da prática do turismo. Como no período atual, os métodos de produção e gestão são flexíveis e a acumulação do capital é realizada numa velocidade cada vez mais rápida e espoliativa, a difusão de novas maneiras para utilizar os recursos naturais ou culturais de um determinado território também se dá de forma intensa, às vezes ocorrendo sem se quer interagir com o local
Geografia Ensino \& Pesquisa, v. 16, n.2 p. 47 - 63, maio/ago. 2012

Silva, C. H. C.

ISSN 2236-4994 | 57 
de sua materialidade. "A atratividade dos lugares (paisagens naturais ou construídas) precisa ser constantemente vendida, então, ela é constantemente recriada, ou melhor, padronizada em estilo, estética e atendimento". (LUCHIARI, 1998, p.24)

Assim, a urbanização turística se caracteriza como um fenômeno que tem se difundido para inúmeras partes do planeta de forma a introduzir, cada vez mais, novas cidades no âmbito do turismo. Deste modo, estamos de acordo com Cruz (2001, p.25) quando afirma que

Cidades podem ser incorporadas, espontaneamente, ao circuito das localidades turísticas, devido à sua valorização (cultural) pela atividade ou, então, induzir o desenvolvimento do turismo, por meio de políticas e do planejamento, caso essa incorporação espontânea não ocorra, direcionando os equipamentos urbanos já construídos e aqueles a construir, em função de uma urbanização para o turismo.

Pelas palavras da Autora percebe-se que, quando o turismo passa a ser visto como uma alternativa para o desenvolvimento econômico, a articulação entre os vários setores da sociedade é fundamental. O planejamento torna-se a principal ferramenta para direcionar os rumos da atividade, já que a vida cotidiana, os velhos costumes e as antigas construções, passarão por grandes modificações em seus rumos, devido ao crescimento do turismo.

\begin{abstract}
Ao se produzir um espaço para ser consumido como lugar turístico, se não houver um planejamento enfocado para o turismo sustentável, destrói-se, dessa forma, as próprias condições que deram origem a este produto, essa mercadoria, que tanto é parte da indústria como do setor de serviços. (YÁZIGI 1999, p.55)
\end{abstract}

Por estas palavras, percebe-se que o enfoque dado para a promoção e desenvolvimento da atividade turística em qualquer que seja a localidade deve prescindir o bom uso dos recursos naturais, culturais e construídos para que o turismo possa ter uma rota de constante crescimento, pois senão, um lugar pode ser considerado top de linha em um determinado momento e, por seu mau uso, em pouco tempo, pode se tornar um local obsoleto, em defasagem e na marginalidade do turismo.

\footnotetext{
Por se tratar de fenômeno social, os estudos e pesquisas que envolvem a atividade turística devem abranger não somente os métodos tradicionais como pesquisa bibliográfica, o inventário do potencial existente e o tratamento das informações com base na metodologia proposta pela EMBRATUR (1992), como também se deve proceder uma análise dessa atividade do ponto de vista da recepção, das atitudes e dos valores dos moradores. (YÀZIGI 1999, p.205)
}

Geografia Ensino \& Pesquisa, v. 16, n.2 p. 47 - 63, maio/ago. 2012

\footnotetext{
O Turismo e a Produção do Espaço:
} Perfil Geográfico de uma Prática Sócioespacial

58

ISSN 2236-4994
Estabelece-se uma relação entre antigas paisagens e velhos usos e novas formas e funções, impulsionando a relação do lugar com o mundo que o atravessa com novos costumes, hábitos, maneiras de falar, mercadorias, modos de agir... Assim também, a identidade do lugar é constantemente recriada, produzindo um espaço social híbrido, 
onde o velho e o novo fundem-se dando lugar a uma nova organização sócio-espacial. (LUCHIARI, 1998, p. 17)

O turismo, a partir deste ponto de vista, ganha força entre os principais vetores do processo globalização, pois tem se mostrado ser um veículo importante das maiores inovações tecnológicas e difusor de novas práticas sociais. Sua ocorrência permite visualizar a relação vital existente entre 0 lugar e o mundo. 0 mundo entendido enquanto virtualidade contém e engloba tudo e todos. O lugar enquanto materialidade apresenta os fragmentos do global apropriados por um certo agrupamento humano. 0 turismo assim, é uma ferramenta importante porque pode levar o mundo a um lugar e conduzir este lugar ao mundo todo, através de novas mercadorias, costumes, hábitos, objetos, etc.

Knafou (1996) estuda as relações entre turismo e território dando ênfase no espaço urbano e destaca a existência de três tipos distintos de situações onde o turismo se relaciona com a cidade. Assim, o turismo pode acontecer junto com o desenvolvimento do espaço urbano, anterior à sua existência, ou posterior.

$\mathrm{O}$ urbano antecede o aparecimento do turismo é a situação mais típica desta relação. Ou seja, as cidades já existiam antes mesmo do turismo se apropriar de seu espaço urbano. Isso se deve ao fato que a urbanização é muito anterior ao fenômeno do turismo como o conhecemos hoje, atividade econômica organizada. As cidades que mais recebem turistas hoje em todo o mundo se encaixam nesta situação. Uma importante modalidade de turismo que se mantém nestas localidades é a voltada ao turismo histórico-cultural, por exemplo.

Quando o desenvolvimento do espaço urbano ocorre em consonância e simultaneidade ao desenvolvimento do turismo, vislumbra-se o processo de urbanização turística do lugar. Ou seja, há uma estreita relação entre ambas e o crescimento do processo de urbanização depende do crescimento da atividade turística. Esta situação é característica por grandes projetos urbanos voltados para o turismo, frutos do planejamento territorial-urbano-turístico. Cidades como Las Vegas, Cancún, Las Leñas e Atlantic City, são alguns exemplos.

A última situação, quando o urbano é posterior ao desenvolvimento do turismo, ocorre quando a atividade está ligada a destinações consideradas selvagens, com difícil acesso e pouca infra-estrutura, mas com um potencial imenso para ser explorado. Na maior parte das vezes são os próprios turistas que "descobrem" estas localidades e, a partir da divulgação entre amigos e parentes (boca a boca), levam o seu nome até os agentes promotores territoriais que trabalham com o turismo que, aos poucos, passarão a investir na localidade levando infra-estrutura e serviços turísticos. Muitas vezes, os próprios turistas pioneiros passam a ser empresários do setor de turismo nestas localidades.

A partir da discussão apresentada pode-se perceber como a atividade turística é dinâmica e possui no espaço, seu maior objeto de consumo. 0 turismo, a partir do consumo do espaço, atua na sua (re)produção de forma que induz a reconfiguração social, cultural e espacial das localidades. A lógica do turismo que hoje se funde à lógica do lazer e do consumo leva aos lugares os mais diferentes atributos do mundo, tornando uma grande ferramenta de difusão do processo de mundialização. O seu perfil sócio-espacial revela a importância da geografia no desvendamento de suas peculiaridades.

\section{Referências Bibliográficas}

ANDRADE, J.V. Turismo: fundamentos e dimensões. São Paulo: Ática, 2000.

Geografia Ensino \& Pesquisa, v. 16, n.2 p. 47 - 63, maio/ago. 2012 
L.N.M.T (org.) Turismo com ética. Fortaleza: UECE, 1998, pp.57-75.

CARLOS, A F.A. A cidade. São Paulo: Contexto, 1992.

Espaço tempo na metrópole. São Paulo: Contexto, 2001.

O espaço urbano: novos escritos sobre a cidade. São Paulo: Contexto, 2004.

CARLOS, A.F.A. e CARRERAS, C. (orgs.) Urbanização e mundialização. São Paulo: Contexto, 2005, 159p.

CASTELLI, G. 3.ed.Turismo: atividade marcante. São Paulo: Moderna, 1999.

CEPOLLARO, G. Gottmann: a metrópole transacional. DE MASI, D. A sociedade pósindustrial. São Paulo: Senac, 2000, pp.233-245.

CRUZ, R.C.A. Introdução à geografia do turismo. São Paulo: Roca, 2001.

Política de turismo e território. São Paulo: Contexto, 2002.

HARVEY, D. Condição pós-moderna. Rio de Janeiro: Ed. Loyola.

HERNAUX NICOLÁS, D. Elementos para um análisis sociogeográfico del turismo. RODRIGUES, A.B. (org.) Turismo e Geografia: reflexões teóricas e enfoques regionais. São Paulo: HUCITEC,1996, pp.39-53.

KNAFOU, R. Turismo e território: por uma abordagem cientifica do turismo. RODRIGUES, A.B. (org.) Turismo e Geografia: reflexões teóricas e enfoques regionais. São Paulo: HUCITEC,1996, pp.62-74.

LEFEBVRE, H. A reprodução das relações de produção. Porto: Escorpião, 1973.

La revolución urbana. Madrid: Alianza, 1983.

A vida cotidiana no mundo moderno. São Paulo: Ática,1991.

LUCHIARI, M.T.D.P. Urbanização turística: um novo nexo entre o lugar e o mundo. LIMA, L.C. (org.) Da cidade ao campo: a diversidade do saber fazer turístico. Fortaleza: UECE, 1998, pp.15-29.

MARX, K. Introdução à crítica da economia política. São Paulo: Abril, vol 35, 1974, pp 109-133.

RODRIGUES, A. B. Turismo e Geografia: Reflexões teóricas e enfoques regionais. São Paulo, Hucitec, 1999.

Uma abordagem geográfica do espaço do turismo. CORIOLANO, L.N.M.T (org.)

Geografia Ensino \& Pesquisa, v. 16, n.2 p. 47 - 63, maio/ago. 2012

O Turismo e a Produção do Espaço: Perfil Geográfico de uma Prática Sócioespacial
Turismo com ética. Fortaleza: UECE, 1998, pp.76-99.

Turismo e espaço: rumo a um conhecimento transdisciplinar. 2.ed. São Paulo: Hucitec, 1999.

Geografia e turismo: notas introdutórias. Revista do Departamento de Geografia. São Paulo: DG/FFLCH/USP, n.6, 1992. pp.71-82. 
SANCHEZ, J.E. Espacio, economia y sociedad. Espanha: Siglo Veintiuno, 1991, pp.216-248.

SANTOS, M. Metrópole Corporativa e fragmentada. São Paulo: Hucitec, 1990.

Por uma economia política da cidade: o caso de São Paulo. São Paulo: Hucitec, 1994, 153p.

SASSEN S. The Global City: New York, London , Tokio. New Jersey: Princeton University, 1988.

TRIGO, L.G.G. A Sociedade Pós-Industrial e o Profissional em Turismo. Campinas: Papirus, 1998.

YAZIGI, E. A alma do lugar. São Paulo: Contexto, 1999.

Civilização urbana: planejamento e turismo. São Paulo: Contexto, 2003.

Organização Mundial do Turismo - www.wto.org

\section{Correspondência:}

Carlos Henrique Costa da Silva - Rodovia Joao Leme dos Santos (SP264) Km110 Bairro Itinga. Sorocaba - SP. 18072-580

E-mail: ricougo@yahoo.com.br

Recebido em 29 de julho de 2011.

Revisado pelo autor em 15 de março de 2012.

Aceito para publicação em 30 de abril de 2012. 